\title{
Rationalising the Teaching Intention of International Postgraduate Student Lecturers
}

\author{
Noluthando Matola ${ }^{1}$, Kehdinga George Fomunyam ${ }^{2, *}$, Simon Bheki Khoza ${ }^{3}$ \\ ${ }^{1}$ Post Graduate Research and Support, Office of the Deputy Vice Chancellor, Durban University of Technology, South Africa \\ ${ }^{2}$ Faculty of Management Sciences, International Center of Non-Violence, Durban University of Technology, South Africa \\ ${ }^{3}$ School of Education, Discipline of Curriculum Studies, University of KwazuluNatal, South Africa
}

Received May 31, 2020; Revised September 10, 2020; Accepted November 2, 2020

\section{Cite This Paper in the following Citation Styles}

(a): [1] Noluthando Matola, Kehdinga George Fomunyam, Simon Bheki Khoza, "Rationalising the Teaching Intention of International Postgraduate Student Lecturers," Universal Journal of Educational Research, Vol. 9, No. 12, pp. 1905 1914, 2021. DOI: 10.13189/ujer.2021.091203.

(b): Noluthando Matola, Kehdinga George Fomunyam, Simon Bheki Khoza (2021). Rationalising the Teaching Intention of International Postgraduate Student Lecturers. Universal Journal of Educational Research, 9(12), 1905 - 1914. DOI: 10.13189/ujer.2021.091203.

Copyright $\mathrm{O} 2021$ by authors, all rights reserved. Authors agree that this article remains permanently open access under the terms of the Creative Commons Attribution License 4.0 International License

\begin{abstract}
Higher education students around the globe have continually searched for opportunities to further their education abroad, looking beyond the provisions of their home country in pursuit of quality education. Most of these students are either tutors, teaching assistants, or in lecturing roles within the university environment. Using a qualitative case-study approach, this paper investigates the teaching intention of international postgraduate student lecturers at a university in KwaZulu-Natal, South Africa. This is in a bid to understand why these students choose to become involved in the teaching and learning process as lecturers. Participants were purposefully selected from a sample population of registered international postgraduate students at the university; and these participants were chosen in an order which ensured representation. Semi-structured interviews and observation methods were used, and data generated were analysed using grounded analysis. Findings reveal that international postgraduate students in this university chose lecturing, owing to the financial preconditions of undertaking postgraduate studies, to improve their interpersonal, communication, and cross-cultural skills, and also owing to legal restrictions. This paper therefore concludes that these reasons are valid and recommend several ways of helping these student lecturers function both effectively and efficiently.
\end{abstract}

Keywords Postgraduate, Teaching, Lecturers, International Students, Rationalising, South Africa

\section{Introduction and Problematic}

Education statistics reveal that sub-Saharan Africa has the highest outward mobility ratio of all the regions of the world, at $4.6 \%$ compared with the world average of $19 \%$ (UNESCO, 2019). This implies that, for every single student enrolled at tertiary level in their home country, 4.6 others have moved away and enrolled abroad. These students who leave their country, or territory of origin, and move to another country or territory, with the single objective of studying, are referred to as international students (UNESCO, 2019). Most higher education students in Africa, for various reasons, continually search for opportunities to further their education abroad. They search repeatedly beyond the provisions of their home countries to pursue high-quality education offered around the globe. The experience obtained from studying abroad has been shown to transform the individual's career path, and aid in building social circles that enhance the individual's global engagement. Study destinations that have time and again dominated their choices include the United States of America, Europe, Asia, and the United Kingdom. Over the past decade, South Africa has seen the second-largest number of African students pursuing high-quality education away from home. South Africa also has the highest growth rate - it recorded a $28.8 \%$ increase in international student enrolment from 2006 to 2010.

Factors that influence the decision of these postgraduate 
students to study in South Africa include the low cost of living compared with other western nations such as the USA, UK, Canada, and Australia. Tuition fees are low, and there is access to advanced modern and technological facilities, the use of English as a medium of instruction, and the international reputation of South African educational qualifications (Mpinganjira, 2015; ICEF Monitor, 2018). The number of international students in South Africa has grown dramatically from 12600 at the time of independence in 1994, to 72875 in 2012. In 2013, South Africa saw close to 74000 international students. Fifteen per cent of these were postgraduate students (ICEF Monitor, 2013). The University of KwaZulu-Natal (UKZN) had some 13064 postgraduate students registered in 2016, with 2209 international students coming from 71 countries (UKZN, 2016). At UKZN, most postgraduate students will engage in teaching at some point during their studies. Some take up teaching assistant roles, while others run tutorials, depending on the opportunities available. The majority of these students are involved in tutoring and lecturing, and as such, it is essential to understand their choice to become involved in the teaching and learning process as student lecturers. A few questions arise: What exactly does the lecturing process entail? Why do most international postgraduate students choose to lecture? What is the impact of this career choice on an average international postgraduate student? To further investigate this issue, it is critical to deconstruct the lecturing process.

\section{Theorising the Lecturing Process}

Lecturing is a term originating from the medieval Latin 'lectura', meaning to read. Often reading was aloud, to illiterate people. This implies that the process of lecturing includes an oral reading of text followed by a commentary (Brown, 1989). Good and Merkel (1959) define lecturing as a mode of teaching in which the teacher orally presents facts and principles to the students. This suggests that the lecturer is the one with all the facts, and his or her duty is to present these facts to the students. The lecture method incorporates a formal disclosure or presentation of knowledge to students; for this reason, traditional teaching, learning and training most frequently rely on lectures. Burkill, Dyer and Stone (2008) comment that lecturing is a one-way communication of prepared talk. Based on the above definitions, lecturing can thus be said to be a one-way channel of communicating information, with the lecturer giving out the information while the students are passive, attempting to grasp information from the instructor. Research has revealed that, although lectures seem to be an efficient teaching method, they do not offer a platform for discussion; therefore, one cannot guarantee that learning has taken place. This conclusion has prompted Marcia (2010) to argue that lecturing consists of presenting knowledge in a manner that helps students to relate it to their own experiences - therefore the lecturer should present knowledge, and offer a platform for the learner to consider how the topic relates to their lives. The goal of every lecturer is for a student to learn during the lectures, thereafter, supporting their learning with activities such as reading lecture notes, or engaging in exercises. If lecturers are to succeed in ensuring learning during lecture time, lecturers must engage processes that enhance durable encoding of facts, concepts, and ideas covered during the lecture. Several scholars (Kember, 1997; Young, 2002; Knight and Wood, 2005; Cotton, Warren, Maiboroda \& Bailey, 2007) have suggested various concepts that can be utilised to ensure the effectiveness of the lecturing process. These key concepts include intention, transmission, receipt of information, and output.

Intention, as the first basic concept, implies that, when lecturing, the lecturer's intention is to deliver a topic as per the syllabus requirements, to generate understanding and to stimulate interest. For a lecture to be considered successful, it must generate understanding. The lecturer should be able to explain key concepts relating to the subject matter. According to Atkins and Brown (2002), if one is able to clearly explain a subject, one has precise knowledge of it. Therefore, in preparing for the lecture, the lecturer is expected to have in-depth knowledge of the topic. The lecturer is also expected to take into consideration the prior knowledge of learners, as far as the topic is concerned. When lecturing, the lecturer also intends to stimulate interest, using individual ability to catch the attention of the students. The second basic concept, transmission, argues that a lecturer sends a message verbally, extra-verbally and non-verbally to the students. The verbal messages may be communicated through a definition of terms, in the process of explaining concepts, or through examples made for emphasis. The 'extra-verbal' component constitutes the lecturer's vocal qualities, hesitations, errors, and use of pauses and silence. The 'non-verbal' component includes the lecturer's gestures, and facial expressions. Rosenshine (1997) postulates that there is a connection between the instructor's vocal variations, and the students' achievement. Rosenshine (1997) adds that the body language of the lecturer influences student learning. The researcher argues that students remember the lecturer's statements better when they are accompanied by the use of non-verbal language. This means that a lecturer should be able to use the right gestures, to enhance student understanding of the subject being consolidated.

Receipt of information, on the other hand, deals with how the information, meaning, and attitudes conveyed by a lecturer may, or may not, be perceived by the students. Concentration will fluctuate in the process of lecturing. Attention is increased if students are engaged in the process; and this may be achieved by granting students an opportunity to engage in discussions, by asking them 
questions, drawing them into problem-solving, and even allowing them to ask questions. The last basic concept of ensuring an effective lecturing process is known as the output. Output deals with learning outcomes expected of the student after the lecturing process. Burkill, Dyer and Stone (2008) argue that an instructional strategy should lead to the objectives and interrelated goals for a course of study. Therefore, students' responses or 'output' is a vital aspect of the process of lecturing. Responses may occur as an immediate reaction to the lecture or the lecturer. A lecturer may change students' perceptions of a problem or theory, increase students' insight, and stimulate the students to read, think, and discuss ideas with one another. Achieving such is largely dependent on the students' knowledge, attitude, and motivation to learn. On the part of the lecturer, results depend on the lecturer's preparation, lecture structure, and presentation. The focus of this research is on the concept of intention, which first analyses the depth of knowledge and understanding the lecturer has on the subject matter. This will help to illustrate what qualifies an international postgraduate student to take up a lecturing role.

\section{The Transition from Student to Lecturer}

Postgraduate studies are considered conduits through which higher institutions of learning develop research capacity. This research takes different forms, but the basic requirement for a student is usually the completion of a bachelor's degree, or a diploma. The requirements for admission to postgraduate programmes may vary from one institution to the other, but the general aim is common. Postgraduate programmes are a mechanism by which graduate students learn how to undertake a systematic investigation, founded upon work, built by peers in the field; thereafter to extend the current state of knowledge in that field (Mutula, 2011). There are variations of postgraduate programmes. Such include postgraduate diplomas, master's degrees, $\mathrm{PhDs}$, inter alia. A postgraduate student is thus one who chooses to undergo any of these postgraduate programmes to grow their skills and become better professionals in their fields of study. Postgraduate students are known as researchers, and the goals of these individuals vary. As stated by Moulding and Hadley (2010), postgraduate programmes offer multiple pathways for students to meet their goals through a wide range of options, including projects and theses. Projects enhance the student's understanding of educational research by enabling them to participate either as critical consumers, or as creative producers of knowledge. One of these pathways is the opportunity given to research students to transition to lecturer.

As posited by Wong (1995), the primary goal of the research is to understand, while the primary goal of teaching is to help students learn. This implies that a student lecturer is expected to learn a body of knowledge about meaningful inquiry and develop an understanding of criteria for quality research. This will enable the postgraduate student to become a better consumer and producer of knowledge. Over time, postgraduate students take up education-related jobs as librarians, technicians, demonstrators, research assistants, and teaching assistants. In recent times, postgraduates have been taking on more significant teaching responsibilities, combining their research studentship with several hours of lecturing, weekly. In particular, postgraduates who are considering a career in academia involve themselves in roles that would involve teaching, supervision, and assessment of undergraduate-level students. They primarily assist and support academic staff, faculty members, or other professional staff members in the delivery of teaching- or learning-related duties to students in a variety of learning environments (Mutula, 2011). Postgraduate student lecturers are progressive, as they are more apt to consider what and how the students they handle learn. Reis-Jorge (2005) insists that their stance is more progressive than traditional pedagogy, and more compatible with the goals of educational research as a reflective practitioner. These students are mature learners with several years of professional experience upon which they draw as they learn new concepts. As evidenced by their commitment to take on graduate study, such students are dedicated to education, and this makes it easier for them to transition to lecturing while studying.

To help postgraduate students make the transition from student to teacher, an experienced professional will often share the classroom with them, imparting to them the knowledge of best practices, and the wisdom acquired from years of experience. Most postgraduate student lecturers begin by working with individuals and small groups of students, gradually graduating to lecturing a full class on their own. For international postgraduate students, this transition is more difficult, as they undergo several challenges, especially since they are to carry out these duties in an unfamiliar environment. Urban \& Palmer (2014) define international students as people temporarily residing in a foreign country for educational purposes. South Africa has been reported to be one of the countries characterised by a steady increase in international student enrolment (Carrim \& Wangenge-Ouma, 2012), because of its reputation in higher education, coupled with reasonable fees. South African universities have also been involved in a strategic plan to increase the number of international students. This is because these students come from very strong academic backgrounds. They enhance cultural diversity in different institutions, and also prepare the student body for the diversity that awaits them in a future place of work. International postgraduate student lecturers face a number of challenges, both academically and non-academically. Challenges include language barriers, cultural shock, financial concerns, neo-racism and xenophobia, as well as unfulfilled academic expectations. 
One of the most common challenges encountered by international postgraduate students is the language barrier. Hammer (1996) defines language barrier as the difficulty experienced by students when there is no common language to communicate with one other. International students come from many different backgrounds; and as such, their language of communication differs from South African students. The use of English as a language of instruction in South Africa has been a major problem for international students. According to Madinga, Maziriri and Lose (2016), this includes the pronunciation, the general meaning of terms used by local and international students, as well as the meaning of certain words in different contexts. Language barriers do not only affect students' ability to learn but also to communicate. In his study, Crose (2011) avers that, even students who are proficient in the English language find the delivery of the English language challenging in a foreign country. In Crose's (2011) study, students stated that the tone and accent used in the English language were different from their native language; and as a result, they found it difficult to comprehend the discussions in the classroom. This, therefore, affects their role as students, and also as lecturers. Second, students studying abroad encounter a whole new world in terms of information, unfamiliar places, behavioural patterns, and types of people. This experience is termed by literature a 'culture shock'. Furnham (2004) defines culture shock as the various emotions individuals feel when arriving in a foreign country. When international students relocate to a foreign country, familiar cues are removed: this results in anxiety for many of them. The degree of stress experienced by foreign students may not necessarily be the same; for example, students coming from South Africa's neighbouring countries may have a similar culture to that of South Africa. Those incomers would have less of a struggle to adapt to life in South Africa, than those coming from afar.

As proposed by $\mathrm{Li}$, Chen, and Duanmu (2010), academic culture shock refers to the differences experienced by international students with regard to the education system, assessments, lecture styles, as well as in the relationships between students and lectures. Another daunting challenge is the issue of finances for international students. Du Plessis and Fourie (2011) reported that international students give sizeable financial contributions to South African universities and the economy of the country, in the form of fees. The fees that these students contribute are usually significantly higher than those paid by local students. Dominguez-Whitehead and Sing (2015) observed that, because the South African Higher Education system has financial challenges, recruiting a large number of international students seems to be the solution to the problem. While some of these students may be economically secure, there are those who experience financial hardship. Donaldson and Gatsinzi
(2005) report that international students from Europe, North America, and Asia have found South Africa affordable, while those from Africa reported a contrasting experience. Self-funded international African students experience major financial challenges (Blake, 2006). In the study by Marringe and Carter (2007), all student participants faced financial anxieties. Some of them were not sure of how they were going to pay their fees. Most of the international students do not have a work permit, which hinders them from gaining work to support themselves.

\section{Research Design and Methodology}

The methodological underpinnings of this research offer an explanation of the approaches used to generate the data used in the paper. This paper adopted a qualitative case-study approach to rationalise the intentions of international postgraduate students lecturing in a university in KwaZulu-Natal. Denzin and Lincoln (2012) define qualitative research as the type of research which studies and gathers detailed empirical data from introspection, personal experience, interviews, documents, and artefacts, which describe in detail problematic situations of phenomena. This approach was suitable for this research as it seeks to locate all information possible about the phenomenon under investigation, so as to generate new knowledge. A case study, on the other hand, is an orderly or comprehensive examination of a particular case in its context in order to generate data (Cohen et al., 2011). It provides an in-depth examination of an incident or example; and analysis in detail of the various examples and phases that make up the life cycle of the unit being explored. In this research, the focus is on international postgraduate students in a university in KwaZulu-Natal. The idea of the research is gaining understanding of the teaching intention of students who choose to lecture while studying.

\section{Participants}

Participants were purposively selected from a sample population of registered international postgraduate students in the university. Chithra and D'Almeida (2014) express that purposive sampling is always used to generate data from people who have specialised knowledge in a field. They argue that it saves time simply to access those who possess the knowledge the researcher needs, rather than randomly sampling a larger population. In this type of sampling, the researcher makes the decision concerning all individuals included in the sample, based on well-thought-out criteria, ranging from specific experiences or specialist knowledge to capacity and/or the willingness by such individuals to take part in the research.

This research adopted purposive sampling. The 
researcher purposely chose participants who are international postgraduates engaged in lecturing, possessing valuable experiences in lecturing in a foreign country. Three lecturers were chosen who are at master's level; and another three from $\mathrm{PhD}$ level were selected, to ensure representation. All participants were available at the university on a daily basis, and as such, were easily accessible to the researcher.

\section{Instrument}

This research utilised two different instruments to generate data, which include semi-structured interviews, and the observation method. Semi-structured interviews use open-ended questions to help the researcher fine-tune the topic being explored. Such interviews also allow the researcher to choose to discuss certain sub-topics in detail, while briefly discussing others, depending on their relevance (Cohen \& Crabtree, 2008). A self-constructed interview guide with open-ended questions posed by the researcher was applied: this guide contained five questions. To ensure a quality interview, the researcher spent ten minutes on each question, fifty minutes being spent on the guide. Issues that emerged during the discussions were also further probed.

The participants spent about three minutes responding to each question. Probing for each answer to the question took about seven minutes. While probing, there was time to examine more deeply the participant's experiences and views. An audio-recording device was used, allowing the researcher to take brief notes during the interview. Interviews were conducted in each lecturer's office (on three separate occasions) for all lecturers involved in the research. The offices were safe and private, enabling the participants to freely share information required by the researcher. The researcher used the non-participant observation method to observe what transpired in the classrooms of the participants, and to gain a better understanding of their experiences. This activity was communicated to the participants before it began so as to make them aware, and to gain permission to be an observer.

\section{Data Analysis}

The content of the interview guide was analysed using grounded analysis, which goes hand in hand with grounded theory. Grounded analysis, which stems from grounded theory, is a procedure for data analysis that refers to the analysis of data without the use of predefined categories or themes, rather allowing the data to speak for itself (Corbin \& Strauss, 2014). In this research, the participnts' responses to the interview were analysed using several processes. The first step applied to the data generated was the open coding. Open coding, according to Corbin and Strauss (2014), refers to the breaking down of data by the researcher into segments, searching for relationships within such segments that could represent themes. The second step applied was axial coding. This, according to Vaismoradi, Turunen and Bondas (2013), refers to the process of breaking each theme into smaller units, thereby unearthing the relationships, context, and/or interaction strategies, amongst others, inherent in each theme. The third step utilized was selective coding, which refers to the process of fine-tuning the themes and sub-themes and weaving them into a storyline or theory which is subsequently explained. The last step is the theory development which entails the compiling of the themes fine-tuned by selective coding, offering an explanation for such. While analysing the data, several measures were taken to ensure that the findings of the study were trustworthy.

\section{Findings and Discussion}

The findings and discussion of this research will be organized according to the major research question which involves understanding the lecturing intention of most international postgraduate student lecturers. This makes it easier to identify patterns in the responses from participants in the research; findings are presented based on the emerging themes from the data. Four main themes emerged from the data, namely: financial support, cross-cultural skills, career advancement, and legal restrictions.

\section{Financial Support}

Funding is an important part of postgraduate studies, especially for international students. The financial preconditions of conducting postgraduate studies involve high expenditure, depending on the kind of research the student is undertaking. Most international students are registered full time, and usually strive for funding. The competition for scholarships is tight, and postgraduate students have to continually apply to various funds, foundations, and institutions for funding. The inability of a postgraduate student to gain external funding would result in the programme having to be self-funded (Kirsi, 2012). A self-funded international postgraduate student needs funds for accommodation, transportation, daily expenses, and studies, which is the primary reason for migrating to South Africa in the first place. One participant corroborates this view:

When you are in another country you need money to survive, lecturing for me also help me financially to sustain myself.

This implies that international postgraduate students see lecturing as a way of securing financial resources to sustain their lifestyles. Most turn to lecturing, as it helps 
them engage fully in their studies, while providing them with some funds. One of the participants, speaking about her experience, pointed out that:

The main reason I took this job was because of financial constraints. I had no one who was supporting me financially, and so I had to lecture

This experience is not unique to this participant, as another participant pointed out a similar experience. She stated:

I came to South Africa as a research student hoping that I would be able to secure funding, but it turned out the only funding available was for local students. Although my family back home was supporting me financially, it was not enough and as such I had to find means to survive while studying, which is when I started looking for a lecturing job.

Financial constraints proved to be a strong rationale for international postgraduate students to lecture. Failing to find funding, they often turn to lecturing as a way of securing finances to meet their needs. A study by Fomunyam (2020) on the experiences of international postgraduate students from Asia and Africa reveals that, Reflecting on their experiences during their doctoral journey, 8 percent of the respondents in this study insist that if given the chance to start over again, they would not consider pursuing a doctorate degree. Most participants wished they had been fully aware of the funding, and financial requirements before commencing their program. Du Plessis and Fourie (2011) argue that international students act as huge sources of income for South African universities. Many of these students find it burdensome to pay the ever-increasing student fees that international students are expected to contribute. The international levy paid by international students, added to their student fees, often brings additional financial constraints, especially for those from other African countries. There is limited financial assistance available for international postgraduate students, as first preference is given to local students.

\section{Personal/Career Advancement}

Khoza (2015) argues that there is a variety of reasons for lecturers to lecture. In the case of international students coming from different countries and backgrounds, these reasons can be as varied as their origin - this is exactly what emerged from the research, as the six participants offered differing reasons or rationales for lecturing. The rationale for each international student depended on a variety of personal and contextual issues. Expounding on this, a participant expressed:

I came to South Africa to study, but we also need to practice what we have been taught. Lecturing is an opportunity that the university gives us to practice what we have been taught. Secondly, it is an opportunity for me to pass across what I have learned. In my masters I wrote a paper on how to write academically, some students don't know how to write academically, so lecturing gives me that opportunity to pass knowledge across.

Lecturing, to this participant, is about self-improvement and gaining more experience; as well as passing on what he has learnt. Another participant added:

Lecturing has always offered me a sense of fulfilment. From the time I started teaching back home, I had always been passionate about sharing my knowledge to others. Also, as a researcher, we need the theoretical aspect of teaching and learning as well as its practical aspect. Lecturing gives me the practical aspect.

Improving their wealth of knowledge by gaining both theoretical and practical knowledge is key to ensuring development for international students. In his study, Fomunyam (2020) postulates that the obvious choice of many doctoral graduates is an academic career in research, and higher education, and this study agrees. This is because over 56 percent of respondents ranked academia as the sector they would most likely work in on completion of their program. 67 percent of respondents believe their postdoctoral program will improve their job prospects, either substantially or dramatically. This increased to 78 percent when exploring results from African respondents specifically. Most doctoral graduates who seek for employment opportunities in academia, experience a smooth transition from doctoral and postdoctoral work, to a full-time position as an academic professor in an institution of higher learning.

Marcia (2010) argues that lecturing encompasses presenting knowledge in such a manner that it helps students relate it to their own experiences, improving themselves. Maiboroda and Bailey (2007), adding to this, remark that intention is the first basic concept of lecturing; and when lecturing, the lecturer's intentions may be as diverse as the topic. To some international students, the intention varies from gaining experience to generating understanding, stimulating interest, and passing on what they have learnt. Another participant states:

...it is part of the package, as a postgraduate you have to practice what you have learned. Postgraduate studies go beyond mere reading and writing you need to practice in order to understand more about your research. Books will not give you enough information on the research that you are doing.

Lecturing, therefore, becomes another avenue for learning for international postgraduate students who are in the university first and foremost to learn. To these participants, lecturing is about gaining experience and putting to work what they have learned, as well as helping other students. Khoza (2015), in line with this, argues that 
lecturers may lecture with the intention of giving back to the community, or improving the lot of the students. Mqadi (2015) adds that, to some lecturers, it is about helping students develop skills that will allow them to reach their full potential and be productive in life. This view resonates with the experiences of some participants, who sought to help students improve their writing abilities, and pass along what the university has imparted to them.

\section{Cross-Cultural Skills}

Studies reveal that cultural factors influence the teaching and learning process, especially the working relationship between teachers and students. International postgraduate students come from different countries, and therefore have different cultural backgrounds (Lu, Chin, Yao \& Xu, 2009). Students studying abroad encounter a whole new world in terms of information, unfamiliar places and behavioural patterns, and people, and this experience is termed by literature a 'culture shock'. Furnham (2004) defines culture shock as the various emotions one feels when moving to a foreign country. Adding to this, Oberg (1960) defines culture shock as the consequence of, and anxiety resulting from, contact with a new culture; and feelings of loss, confusion, and impotence which are owed to the loss of accustomed cultural cues and social rules. The excitement of coming into a foreign country is often dimed by the feeling of uncertainty, and the expectations, and orientation of the new environment and culture (Ramachandran, 2011; Yilmaz, 2017).The degree of shock experienced by these students differs, depending on how prepared they are for the new environment, the cultural knowledge and identity, their expectations, the availability of support systems, the degree of differences between their culture and the new culture, as well as their individual personality traits (Yost \& Lucas, 2002).

The use of English as a language of instruction in South Africa has, as mentioned, been a major problem for international students. According to Madinga, Maziriri and Lose (2016), the English language uses unique pronunciation which alters the general meaning of terms as pronounced by local and international students, as well as the meaning of certain words in different contexts. In South Africa, international students come from vastly different backgrounds. Some come from French- or Portuguese-speaking countries and others have various indigenous languages. For some of these students, they are communicating in English (Heikinhend \& Shute, 1986) for the first time. Some international postgraduate students take up teaching jobs as this improves their language skills and develops their interpersonal communication skills. Other cross-cultural issues arise from teaching methods, learning attitudes and styles, and most importantly, the relationship between lecturer and student.
In a cross-cultural environment such as a university environment, students and lecturers interact with different expectations and understanding. According to a participant:

...the issue of background, for example I like to make a joke in class to make my students calm but initially I didn't know that South Africa is a country that is sensitive to some jokes, there I some jokes I could share in my class back home and people would not be offended but here it can cause a lot of trouble, like the issue of gender, back home we there is no much tension on the issue of gender and race, but here you have to be careful if you want to make any example.

Taking up these lecturing jobs affords international postgraduate students the opportunity of learning suitable teaching and learning methods required in their new environment. A participant further stated:

When I started here, there was an example I made about Christians and Muslim and it caused a lot of trouble for me and I didn't know. It was later that one of the senior lecturers corrected me and told me that topic was very sensitive, and I should never raise it in class. And one time a student made a joke about my country and everybody laughed, and I was offended, I tried to tell coordinator about it. There some things that I need to understand that this is no longer my country, I had to learn about the culture here.

The teaching and learning attitudes, styles, and perceptions these student lecturers encounter afford them the art of adaptation. Therefore, international postgraduate student lecturers in South African institutions of higher learning take up lecturing jobs in order to adopt teaching and learning skills needed in unfamiliar environments.

\section{Legal Restrictions}

Around the globe, most international students are not allowed to work outside the university environment. Laws are put in place to prevent students on student visas in a foreign country from legally working either full or part time, for several reasons. Some of these laws apply in South Africa, where foreign students who choose to study in South Africa, regardless of the level, must apply for a student visa before entering the country. The stipulations of this visa are sometimes stringent, and do not favour students who want to work, attending school part time. Selvadurai (1991) and Dominguez-Whitehead \& Sing (2015) observe that, often, international students face financial problems, because the legal implications of studying here require them to register as full-time students. International students are not allowed to work in South Africa, even though provision has been made for students who have to do practical work as part of their research, at 
either the university where they are studying, or a related organisation.

Owing to financial concerns, most international postgraduate students choose to find jobs within the campus environment, and these jobs are in short supply. Some students therefore choose lecturing if they find the opportunity, since they cannot take regular day jobs elsewhere. Most international students do not have work permits. Their study conditions only allow them to work twenty hours a week, which hinders them from gaining work which could properly support them. The only opportunity they have, therefore, to improve their financial circumstances, is to turn to lecturing. One participant sheds more light on this by explaining:

When you are in another country you need money to survive, lecturing for me also help me financially to sustain myself

Financial constraints therefore push most postgraduate students to engage in lecturing, as this is one of the legal ways in which they can earn extra money to support themselves while studying. Trice (2003) argues that international students have distinct academic and personal needs. They most often try to deal with this by filling research assistant vacancies, thus helping to establish international ties. Alternative perspectives and perceptions of life can be imparted to others via lecturing. Lecturing becomes a coping mechanism for dealing with a variety of issues.

\section{Conclusions and Recommendation}

This research investigates international postgraduate student lecturers in a university in South Africa, in a bid to understand their teaching intentions. Findings reveal that the choice of South Africa as a study destination for most of these students includes affordable tuition fees compared with Western institutions, low cost of living, the presence of modern technological facilities, quality education, and the use of English as a medium of instruction. This research finds that international postgraduate students choose to lecture for several reasons. First, the financial preconditions of undertaking postgraduate studies involve a great deal of expense, including accommodation, transportation, daily needs and contingencies. The competition for scholarship is tight. Preference is given to local students, leaving international students to fund their studies themselves. Most of these students, therefore, take up lecturing jobs to generate funds in order to augment the financial support they receive from family back home. Therefore, financial constraints prove to be a valid rationale for international postgraduate students to take up lecturing jobs.

Second, some of these students perceive lecturing as an avenue by which to gain experience and facilitate self-improvement. Students, who intend to pursue a career in academics, find especially that lecturing improves their wealth of knowledge both theoretically and practically. Third, developing the ability to adapt to unfamiliar cultural environments is also a rationale behind the intention of some international postgraduate student lecturers. Obtaining cross-cultural skills is vital. Entrance into a new society often causes "culture shock". In a cross-cultural environment such as a university, it is essential for lecturers and students to develop an excellent working relationship, in order to provide seamless learning. Functioning as a lecturer enables the student to improve interpersonal communication skills, gaining suitable teaching and learning skills needed for adaptation to any unfamiliar environment in which they find themselves. Last, these international postgraduate students choose lecturing as it is one of the few available legal avenues to generate funds.

This research therefore recommends that international postgraduate students engaged in lecturing should be properly inaugurated into their various universities, with provision made to carefully introduce them to the culture inherent in their environment. Such provision could be in form of training and development interventions, which would expose them culturally to the norms of their new environment. These student lecturers could be enrolled in non-compulsory language classes, in which they would be taught the basics of the local language, thereby being able to relate better to their students. Furthermore, exposure to the belief systems of the various societal groups that make up students in the classroom is also important. Some of these lecturers reported that they had learnt in their classrooms the sort of remarks unacceptable in South African society and culture; these teachers had not known such beforehand. Organising cultural training and events will better prepare student lecturers to handle their students more sensitively. In her study on cross-cultural mentoring relationships between trainee teachers and their mentors, Schafer (2014) concludes that it is important not to ignore the culture shock that some international students experience. This study by Schafer recommends an induction period for these students, which will involve pairing them with mentors that could alleviate potential challenges. Finally, student lecturers should be supported financially through available scholarship provisions or grants for their studies. International students are not legally allowed to take proper gainful employment. The stress of funding themselves provides an unwarranted distraction from both lecturing and learning, which is their raison d'ẹtre, after all. Aiding international postgraduate students to function effectively and efficiently will therefore involve easing their financial stress.

\section{REFERENCES}

[1] Abdullahi, M. S., Abubakar, A., Aliyu, R. L., Umar, K., 
Umar, M. B., Sabiu, I. T., Naisa, K. U. F., Khalid, S. S., \& Abubakar, S. L. (2015). The nature of Small and Medium Scale Enterprises (SMEs): government and financial institutions support in Nigeria. International Journal of Academic Research in Business and Social Sciences, 5(3), 525-537.

[2] Aganga, O. (2015, May 22). MSMEs employ 60m Nigerians, accounts for $48 \%$ of GDP [Online news media]. Retrieved from https://www.vanguardngr.com $/ 2015 / 05 / \mathrm{ms}$ mes-employ-60m-nigerians-accounts-for-48-of-gdp/

[3] Aigbavboa, C., Oke, A. E., \& Mpho, D. M. (2016). Implementation of skill development act in the South African construction industry. The Scientific Journal for Theory and Practice of Socio-economic Development, 5(9), 53-64.

[4] Augustine, A. (n.d.). 5 Strategies that will turn your employees into leaders. Retrieved from https://www.themuse.com/advice/5-strategies-that-will-turn -your-employees-into-leaders

[5] Capacity Development Centre (2012). Empowering SMEs in Ghana for global competitiveness. Retrieved from http://www.modernghana.com/news/407750/0/empowering -smes-in-ghana-for-global- competitivenes.html

[6] Chua, C. (n.d.). Skills Development. Retrieved from https://personalexcellence.co/blog/skills-development/. Accessed on 30/08/19.

[7] Chimucheka, T. (2014). Entrepreneurship education in South Africa. Mediterranean Journal of Social Sciences, $5(2), 403-416$.

[8] Doyle, A. (February 4, 2019). Hard skills vs. soft skills: What's the difference? [Online News Media]. Retrieved from

https://www.thebalancecareers.com/hard-skills-vs-soft-skill s-2063780

[9] Elphick-Moore, D. (November 8, 2012). Skills development defined [Online News Media]. Retrieved from https://www.experthub.info/business/staff/increasing-produ ctivity/skills-development-defined/

[10] Essiet, D. (February 22, 2017). Building skills to reduce unemployment [Online News Media]. Retrieved from https://thenationonlineng.net/building-skills-reduce-unempl oyment/. Accessed on 30/08/19.

[11] Ezeani, N. S. (2012). The teacher and skills acquisition at business education: From the perspective of accounting skills. Arabian Journal of Business and Management Review, 2(4), 25-36.

[12] Fomunyam, K.G. (2020). Theorising Intercontinental PHD Students' Experiences: The case of Students from Africa and Asia. International Journal of Higher Education, 9(3): 32. DOI: 10.5430/ijhe.v9n3p232

[13] Franklin, A., \& William, Jimoh. (October 17, 2013). Eighty per cent of SMEs fail within 5 years [Online News Media]. Retrieved from https://www.vanguardngr.com/2013/10/eig hty-per-cent-smes-fail-within-5-years-finance-experts/. Accessed on 30/08/19.

[14] Gartenstein, D. (April 20, 2018). Why Is Strategic Planning Important to an Organisation? Retrieved from https://yourbusiness.azcentral.com/strategic-planning-impor tant-organization-4103.html

[15] Gebre, M. (April 4, 2019). Africa's youth unemployment rate to exceed $30 \%$ in 2019: ILO [Onine News Media]. Retrieved from https://7dnews.com/news/africa-s-youth-un employment-rate-to-exceed-30-in-2019-ilo

[16] Hansen, M. (2018). How to develop and train for soft skills in the workplace. Retrieved from https://elearningindustry.c om/soft-skills-in-the-workplace-develop-train. Accessed on $31 / 08 / 19$

[17] Ibrahim, M. Y. (2017). Influence of business education curriculum on entrepreneurial skills of colleges of education graduates in North-Central Zone, Nigeria. A thesis submitted to the school of postgraduate studies, Ahmadu Bello University, Zaria.

[18] Kawar, M. (2011). Skills development for job creation, economic growth and poverty reduction. Retrieved from https://www.ilo.org/wcmsp5/groups/public/---arabstates/---r o-beirut/documents/genericdocument/wcms_210671.pdf

[19] Kileo, M. (2016). Importance of financial management. Retrieved from https://www.linkedin.com/pulse/importance -financial-management-hamza-kileo

[20] Lesonsky, R. (December 5, 2018). 10 Skills Your Employees Need to Succeed [Online News Media]. https://smallbiztrends.com/2013/01/10-skills-employees-ne ed-succeed.html

[21] Michael, G. (September 10, 2018). Should South African schools introduce entrepreneurship as a subject? [Online News Media]. Retrieved from https://www.parent24.com/L earn/High-school/should-south-african-schools-introduce-e ntrepreneurship-as-a-subject-20180131. Accessed on $31 / 08 / 19$

[22] Muriithi, S. (2017). African small and medium enterprises contributions, challenges and solutions. European Journal of Research and Reflection in Management Sciences, 5(1), $36-48$.

[23] Nirav, P. (November 21, 2018). Figure of the week: Understanding poverty in Africa [Online News Media]. Retrieved from https://www.brookings.edu/blog/africa-in-f ocus/2018/11/21/figure-of-the-week-understanding-poverty -in-africa/

[24] OECD (2004). 2nd OECD conference of ministers responsible for small and medium-sized enterprises (SMEs). Promoting entrepreneurship and innovative SMEs in a global economy: Towards a more responsible and inclusive globalization. Istanbul, Turkey. http://www.oecd.org/sti/sm es

[25] Okereke, L. C., \& Okorafor, S. N. (2011). Entrepreneurship skills development for Millennium Development Goals (MGDs) in business education. Business Education Journal, $1(11), 83-88$

[26] Olivier, H. (October 13, 2017). Eight challenges facing the African SME [Onine News Media]. Retrieved from https://www.biztechafrica.com/article/eight-challenges-faci ng-african-sme/12940/. Accessed on 30/08/19.

[27] O’Neil, B. (April 13, 2017). 7 important business skills you need today [Online News Media]. Retrieved from 
https://collegeforadultlearning.edu.au/7-important-businessskills/. Accessed on 30/08/19.

[28] Project Management Institute (n.d.). What is Project Management? Retrieved from https://www.pmi.org/about/le arn-about-pmi/what-is-project-management

[29] Ramachandran, N,T. (2011). Enhancing International Students Experiences: An Imperative Agenda for Universities in the UK. Journal of research in International Education, 10(2), 201-220.

[30] Robu, M. (2013). The dynamic and importance of SMEs in economy. The USV Annals of Economics and Public Administration, 13(17), 84-89.

[31] Savlovschi, L. I., \& Robu, N. R. (2011). The role of SMEs in modern economy. Economia. Seria Management, 14(2), 277-281.

[32] Schafer, I. (2014). How do International Trainee Teachers and Mentors Respond to Cross-Cultural Mentoring Relationships. Worcester Journal of Learning and Teaching, Issue 9. Retrieved from: https://rteworcester.files.wordpress .com

[33] Sharma, S. (November 16, 2018). What is the skill development? Retrieved from https://www.quora.com/What -is-the-skill-development

[34] Yilmaz, D.V. (2017). Studying Abroad. Experience of international Students in a Turkish University. Journal of Higher Education, 8(1):23-32 